\title{
O currículo das escolas do campo analisado nas Cartas Cirandeiras
}

\author{
The curriculum of the country school analyzed in \\ the Letters Cirandeiras
}

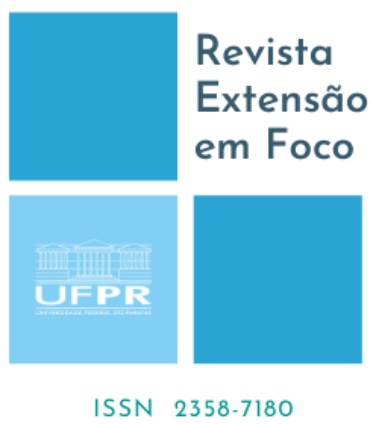

\author{
Aline Guterres Ferreira ${ }^{1}$, José Vicente Lima Robaina ${ }^{2}$.
}

\begin{abstract}
RESUMO
São reconhecidas as necessidades da adequação curricular e metodológica para as escolas do campo, como uma das formas de sanar os anos de exclusão e também como meio de resistência dos conhecimentos e saberes das populações do campo. A pesquisa possui objetivo de refletir sobre os currículos das escolas do campo, no que tange a Pedagogia da Alternância e a Agroecologia, a partir das contribuições das áreas do conhecimento das ciências da natureza e das ciências agrárias. Sendo as escolas em estudos originárias das "Maison Familiales Rurales" francesas, onde são organizadas metodologicamente a partir da práxis da Pedagogia da Alternância, com ensino baseado na Agroecologia. Foram estudadas duas experiências de Escolas Famílias Agrícolas do Estado do Rio Grande do Sul, no que tange os conceitos que embasam seus trabalhos e as contribuições das ciências para a construção do conhecimento. Visto que, essas escolas do campo ofertam o ensino médio integrado ao técnico profissionalizante no meio rural. A pesquisa é de cunho qualitativo, parte de analises documentais, referente ao Plano de Curso dessas instituições escolares, com base em um roteiro previamente organizado de acordo com os objetivos do estudo. Além de fazer parte do projeto Cirandar: Rodas de investigação desde a escola da Universidade Federal do Rio Grande, que conduziu as reflexões desse processo investigativo a partir de Cartas Cirandeiras. São demonstrados os avanços na concepção da integração do conhecimento a partir de ferramentas que promovem a construção dos saberes entre as escolas do campo e comunidade rural.
\end{abstract}

Palavras-chave: Educação do Campo. Agroecologia. Pedagogia da Alternância.

\section{ABSTRACT}

The needs for curricular and methodological adequacy for rural schools are recognized, as one of the ways to remedy the years of exclusion and also as a means of resisting the knowledge and knowledge of rural populations. The research aims to reflect on the curricula of rural schools, with regard to Pedagogy of Alternation and Agroecology, based on the contributions of the areas of knowledge of the natural sciences and agricultural sciences. As schools in studies originate from the French "Maison Familiales Rurales", where they are methodologically organized based on the practice of Pedagogy of Alternation, with teaching based on Agroecology. Two experiences of Family Agricultural Schools in the State of Rio Grande do Sul were studied, with regard to the concepts that support their work and the contributions of science to the construction of knowledge. Since, these rural schools offer secondary education integrated to the professional technician in rural areas. The research is of a qualitative nature, based on documentary analyzes, referring to the Course Plan of these school institutions, based on a script previously organized according to the objectives of the study. In addition to being part of the Cirandar: Rodas de Investigación project from the school of the Federal University of Rio Grande, which led the

\footnotetext{
${ }^{1}$ Doutoranda em Educação em Ciências: química da vida e saúde da Universidade Federal do Rio Grande do Sul (UFRGS). Mestra em Extensão Rural (UFSM). Porto Alegre, RS, Brasil. E-mail: alinegufe@gmail.com. ORCID: https://orcid.org/0000-0002-4288-9907.

${ }^{2}$ Pós Doutor em Educação e Educação do Campo (UFRGS). Docente Adjunto (UFRGS). Porto Alegre, RS, Brasil. E-mail: joserobaina1326@gmail.com. ORCID: https://orcid.org/0000-0002-4604-3597.
} 
reflections of this investigative process based on Letters Cirandeiras. Advances in the conception of knowledge integration are demonstrated using tools that promote the construction of knowledge between rural schools and rural communities.

Keywords: Rural Education. Agroecology. Alternation Pedagogy.

\section{INTRODUÇÃO}

O ano de 2020 trouxe muitos desafios nunca antes imaginados por nossa geração. A Pandemia do Sars-CoV-2 oriundos do novo coronavírus veio a somar em um ambiente de caos e hostilidade que o Brasil já estava vivendo, com a sistemática retirada de direitos dos trabalhadores(as) e aposentados(as) e a degradação ambiental em níveis alarmantes. Quando analisada a educação nesse contexto, são expostos os abismos entre as instituições públicas e privadas, resultado de anos de sucateamento e descasos com as escolas públicas.

No meio rural, essas desigualdades são ainda mais acentuadas e visíveis, pois historicamente à essa população é negado o direito à escola e o acesso às tecnologias. Quando analisados os processos históricos vividos pelas populações do campo, é transparente a exclusão tecnológica e escolar, no momento em que são fechadas as escolas no meio rural em prol da centralização urbana, bem como a rarefação de pontos de internet e até mesmo da rede de energia elétrica, que para muitos ainda não existe.

Em oportunidade, essas questões são trazidas a luz nas Cartas Cirandeiras do seguinte projeto de extensão "Cirandar: Rodas de investigação desde a escola" da Universidade Federal do Rio Grande (FURG), oriundo dos Encontros Riograndinos sobre Investigação na Escola FURG. Projeto esse já reconhecido e consolidado nas redes de educação e pesquisas no Rio Grande do Sul (RS), desde a escola básica até os programas de pós-graduação das Universidades e Institutos Federais e instituições privadas.

A edição 2020 do projeto Cirandar foi conduzido e sistematizado pela coordenação na FURG junto aos organizadores dos Polos regionais, da região sul do Brasil, por meio de troca de Cartas (via correio eletrônico) e web-reuniões. Cartas que encaminham a reflexão a partir de questões e análises da conjuntura. A primeira Carta solicita uma apresentação criativa do participante do projeto, o(a) Cirandeiro(a), a segunda Carta nos convida a apresentar uma temática de pesquisa/estudo que será aprofundado na terceira Carta. Essas escritas culminam em uma produção final, a qual será avaliada/considerada por uma leitura entre pares, dentre todos os participantes do projeto. Nesta última edição 
do projeto Cirandar houve a necessidade de adaptação ao distanciamento social, portanto este foi desenvolvido por meio de encontros virtuais síncronos, e-mails e grupos de trocas de mensagens.

Neste artigo abordaremos a temática de estudo desenvolvida no projeto Cirandar 2020, o qual possui o objetivo de refletir sobre os currículos das escolas do campo desenvolvidos nas Cartas do projeto, tendo como pano de fundo a condução questionadora e reflexiva da coordenação.

\section{EDUCAÇÃO DO CAMPO \& AGROECOLOGIA}

É compreendido por grande parte da comunidade educadora e pesquisadores da área da educação as necessárias adequações curriculares e metodológicas nas escolas do meio rural que atendem as diversas populações que compõem o campo brasileiro. Já detectamos a superação da nomenclatura de educação rural, intrinsicamente ligada ao Ruralismo Pedagógico para Educação do Campo, assim como destaca a autora Roseli Caldart (2002, p. 19): "trata-se de uma educação dos e não para os sujeitos do campo. Feita sim através de políticas públicas, mas construídas com os próprios sujeitos dos direitos que as exigem.". Visto que, não é mais admissível a transferência dos currículos das escolas urbanas para as escolas do campo e muito menos o fechamento dessas nas comunidades rurais, como afirma ainda a autora, "uma educação que seja no e do campo. No: o povo tem direito a ser educado no lugar onde vive; Do: o povo tem direito a uma educação pensada desde o seu lugar e com a sua participação, vinculada à sua cultura e às suas necessidades humanas e sociais.” (2009, p. 149). Assim sendo, abordaremos a Pedagogia da Alternância e o ensino da Agroecologia como modelo e alternativa à educação rural, construído junto as comunidades do campo.

As escolas aqui estudadas organizam-se pedagogicamente na proposta metodológica da Pedagogia da Alternância, que segundo a autora Cristina Vergutz.

[...] movimento singular dessa proposta educativa que está embasada originalmente na relação estudante-família-escola e organizada no processo da alternância de espaço e tempo entre a família e a escola. Assim, o estudante permanece uma semana imerso nas vivências da família e de suas atividades na propriedade agrícola, denominada sessão familiar, e uma semana na sessão escolar onde interage e vivencia o espaço e o tempo escolar com atividades disciplinares e de convivência com o grupo de estudantes e monitores. [...] Isto permite relacionar as matrizes culturais imanentes ao viver no próprio método da Pedagogia da Alternância, isto é, a interação do viver na própria ação educativa, sintonizando os saberes, os acontecimentos e as vivências que emergem fora e dentro da escola e da família. (VERGUTZ, 2013, p 19 - 20). 
A Educação do Campo possui na sua gênese a Pedagogia da Alternância e com ela são construídos os diversos referenciais que subsidiam e constituem o movimento pela Educação do Campo. Entre esses, destacamos o estudo da Agroecologia para a diversificação cultural, valorização dos conhecimentos ancestrais e o engajamento social, entre outros. Como destaca o autor Caporal.

\begin{abstract}
A Agroecologia é uma ciência que busca conhecimentos de diferentes fontes seja o conhecimento empírico ou as contribuições de muitas disciplinas científicas para a partir da integração desses distintos conhecimentos, adotar um enfoque holístico e uma abordagem sistêmica, capazes de contribuir: a) para a compreensão das razões e elementos que determinam a insustentabilidade dos modelos dominantes de desenvolvimento rural e de agricultura convencional e, b) propor caminhos mais compatíveis com ideias de sustentabilidade. A Agroecologia é uma ciência que incorpora uma concepção de sustentabilidade [...] está alicerçada nas noções de solidariedade intra e intergeneracional. (CAPORAL, 2009, p. 23 - 24).
\end{abstract}

Entende-se que a Agroecologia subsidia teórica e metodologicamente a Educação do Campo junto a Pedagogia da Alternância nas escolas do campo aqui estudadas, as quais compõem os Centros Educativos Familiares de Formação em Alternância (CEFFA's), sendo as Escolas Famílias Agrícolas (EFA`s), Casas Familiares Rurais (CFR's) e Escolas Comunitárias Rurais (ECR’s).

Apresentados os referenciais, a proposta deste artigo especificamente parte da reflexão dos currículos dessas escolas do campo, no que tange a Pedagogia da Alternância e a Agroecologia, a partir das contribuições das áreas do conhecimento das ciências da natureza e das ciências agrárias. Visto que essas escolas do campo ofertam o ensino médio integrado ao técnico profissionalizante na área agrícola.

\title{
METODOLOGIAS
}

A partir das Cartas enviadas aos Cirandeiros(as) no decorrer de 2020/21, das reuniões organizadas nos Polos do projeto, das conversas e reflexões construídas em grupo propusemos uma análise dos currículos das escolas do campo, mais especificamente das EFA's, no que tange a Pedagogia da Alternância como práxis e o ensino da Agroecologia.

Trazemos a luz da discussão a construção do conhecimento em Agroecologia a partir de diferentes áreas dos conhecimentos, as ciências da natureza e as ciências agrárias, e seus diálogos mediado pelos Instrumentos Pedagógicos da Pedagogia da Alternância. 
Na primeira Carta do projeto Cirandar, somos convidados a nos apresentar a partir da seguinte questão "Como cheguei até aqui?". E a minha Carta resposta parte das primeiras vivências nessas escolas do campo, em meados de 2010/11, durante a graduação em Zootecnia e o Mestrado em Extensão Rural na Universidade Federal de Santa Maria (UFSM), com a escrita da minha Dissertação. Onde analisei a primeira Escola Família Agrícola (EFA) no RS, sua história e desenvolvimento na região central do Estado. Assim, construo minha apresentação a partir desse momento de formação, do nascimento de uma pesquisadora e do comprometimento com os fatos, as metodologias e as análises a partir dos métodos científicos, respeitando assim a construção científica das instituições de ensino.

Na segunda Carta nos é solicitado apresentar a temática de estudo, questões que nos atravessam, que são problemáticas às nossas pesquisas. Respondi anunciando os altos, presentes e persistentes índices de analfabetismo no meio rural e o crescente fenômeno do êxodo rural, que causa o esvaziamento e empobrecimento do campo brasileiro. $\mathrm{Na}$ terceira Carta é aprofundado o estudo sobre a temática apresentada anteriormete, considerando toda a trajetória construída no projeto em conjunto com os demais Cirandeiros(as) e as análises pertinentes à pesquisa realizada. Essas três Cartas culminam em uma produção final que será avaliada entre pares, pelos demais participantes do projeto Cirandar, dentre os demais Polos. Esta avaliação possui intuito de contribuir com a escrita e as reflexões dos(as) Cirandeiros(as) e não de corrigir a produção.

A pesquisa construída para essa edição do projeto Cirandar, partiu de estudos realizados sob o currículo das áreas de conhecimento das ciências da natureza e das ciências agrárias de duas escolas do campo, que não serão identificadas, mas seguem o modelo Escola Família Agrícola (EFA) e estão localizadas no Estado Gaúcho. O estudo tange a práxis da Pedagogia da Alternância com os desenvolvimentos dos Instrumentos Pedagógicos e suas contribuições para o ensino de Agroecologia.

A pesquisa é de cunho qualitativo, pois segundo Martins (2004) os fatos da vida social são complexos e o cenário de vários fenômenos são impossíveis de serem reproduzidos dentro de laboratórios e submetidos a controle, além de serem de difícil separação das causas e de suas motivações isoladas e exclusivas. E parte das análises dos Planos de Cursos dessas instituições escolares onde estão descritos os currículos das áreas de conhecimentos estudadas e os aportes teóricos sobre a Pedagogia da Alternância e os Instrumentos Pedagógicos, caracterizando assim, uma pesquisa e análise documental. De acordo com Gil (2009), a pesquisa documental é o estudo sob materiais que não passaram 
por um tratamento analítico, ou que ainda podem ser reelaborados de acordo com os objetivos da pesquisa, é o primeiro passo, que consiste na exploração das fontes documentais.

Assim, debruçamo-nos sobre os documentos oficiais dessas instituições escolares com um roteiro de pesquisa previamente elaborado de acordo com os objetivos deste estudo. Que consiste, especificamente, em enxergar e analisar as contribuições que as diferentes áreas do conhecimento, ciências da natureza e ciências agrária, proporcionam para a construção do conhecimento em Agroecologia, promovidos pela Pedagogia da Alternância e seus Instrumentos Pedagógicos. Neste roteiro de pesquisa, buscamos enxergar nesses documentos os conceitos que componham a Pedagogia da Alternância e os Instrumentos Pedagógicos, assim como as definições e colaborações que essas ferramentas promovem à construção do conhecimento e as potencialidades dessas metodologias para a Educação do Campo.

\section{ANÁLISES E DISCUSSÕES}

A Pedagogia da Alternância nasce na década de 30 no meio rural francês, para atender filhos de agricultores insatisfeitos com a educação da época, inacessível e descontextualizada. Nas "Maison Familiales Rurales" (em livre tradução, Casas Familiares Rurais) a educação era organizada em alternância, onde os estudantes transcorriam o período de uma semana na Paróquia da comunidade rural, com a tutela dos padres e agentes sindicais e as outras três semanas retornavam às famílias. Ocorrendo assim uma formação completa no que tange os aspectos da formação técnica, humana e geral, sendo este um dos diferenciais deste novo sistema educacional, a formação integral dos estudantes, que futuramente receberia o nome de Pedagogia da Alternância. Nas décadas seguintes, está nova experiência educacional se expande pela Europa e chega ao Brasil no final dos anos 60 pelo Estado do Espírito Santo, vinculado ao Movimento de Educação Promocional do Espírito Santo (MEPES). No RS o modelo EFA chega em 2009 e atualmente existem quatro instituições escolares gaúchas desta experiência.

No Plano de Curso da EFA estudada, é descrito esse sistema a partir de seus movimentos e as potencialidades de educação, quando reconhecida a continuidade e complementaridade da formação do estudante no ambiente familiar/comunitário. 
A Pedagogia da Alternância se caracteriza por alternar a formação do aluno entre momentos no ambiente escolar e momentos no ambiente familiar/comunitário. A proposta é desenvolver um processo de ensinoaprendizagem contínuo em que o aluno percorre o trajeto propriedade - escola - propriedade. (PCEFA, 2012, p. 03).

Destacamos ainda deste novo modelo educacional o reconhecimento e a valorização dos conhecimentos de outros espaços que não somente a escola, como as famílias e comunidades de origem dos estudantes. Identificamos que essa expansão do território educacional, para além dos muros escolares, torna o processo educativo mais significativo e legítimo aos estudantes e suas famílias, ao reconhecerem suas práticas e sabedorias em conjunto as aulas escolares, incorporando-as ao currículo escolar.

O Desenvolvimento do Meio, a nível social, ambiental, econômico, humano, político, é um dos pilares fins da Pedagogia da Alternância, junto com a Formação Integral do jovem por um projeto pessoal de vida. Possui como meios para chegar a esses fins a Alternância, como uma metodologia pedagógica adequada junto com a Associação Local formada pelos pais, famílias, profissionais e instituições. Essas instituições escolares preconizam o desenvolvimento integral do estudante junto aos seus territórios de abrangência na perspectiva do desenvolvimento rural sustentável, solidário e cooperativo. Encontramos essa perspectiva educacional na Matriz Curricular no Plano de Curso das EFA's estudadas com a oferta do componente curricular intitulado “Agroecologia" ou "Agroecologia e Ecossistemas" entre 60 e 80 horas anuais. Onde são desenvolvidas reflexões e práticas de produção de alimentos sustentáveis aos níveis econômicos, sociais e ambientais, com base num vasto referencial teórico da área e ainda com os conhecimentos de origem dos estudantes trazidos via os Instrumentos Pedagógicos da Pedagogia da Alternância.

Os Instrumentos Pedagógicos promovem a conexão dos conhecimentos dos diferentes territórios que os estudantes percorrem durante os momentos da alternância, permitindo assim a construção e a elaboração de conhecimentos mais legítimos e significativos aos estudantes, como podemos destacar com autor Costa.

Os instrumentos pedagógicos são as ferramentas que permitem a partilha e a elaboração dos conhecimentos advindos da família/comunidade para a escola, que tem por obrigação a construção de uma reflexão com os estudantes, que retornam essa elaboração para a sua família/comunidade, em muitos casos experimentando esse "novo" conhecimento na propriedade. (COSTA, 2012, p. 170). 
Dentre essas ferramentas utilizadas pelas escolas do campo, daremos destaque ao Plano de Estudo (PE), o qual se caracteriza como um instrumento de ligação entre o espaço escolar e o espaço sociofamiliar (família, propriedade familiar e comunidade rural), promovendo o diálogo entre esses ambientes. As características e significados do PE são encontrados no Plano de Curso da EFA estudada, a seguir.

O Plano de Estudo é o canal de entrada da cultura popular para a Escola Família
Agrícola e é o responsável de levar para a vida cotidiana as reflexões, as
questões e as conclusões. Guia elaborado pelos professores e alunos ao final
de uma sessão escolar, o Plano de Estudo permite que os temas ligados ao
contexto vivido pelo aluno se tornem o eixo central de sua aprendizagem. A
princípio, o aluno desenvolve temas mais simples ao cotidiano familiar, para
depois caminhar em direção a temas mais complexos de caráter
socioeconômico. (PCEFA, 2008, p. 52).

Visto que o Plano de Estudo se caracteriza por trazer a realidade dos estudantes para dentro da escola do campo, para que esses sejam desenvolvidos juntos aos conteúdos curriculares trabalhados em aula, este torna-se a ponte entre a experiência familiar e o conhecimento técnico científico historicamente construído pela humanidade e traduzido nas disciplinas escolares, permitindo assim uma aprendizagem mais coerente com as necessidades locais.

Por vezes não são apresentados nos documentos curriculares das escolas do campo estudadas, distinções e divisões tradicionais das áreas dos conhecimentos da educação básica e do técnico. Visto que a organização curricular destas, parte da concepção da integração das disciplinas do curso médio e do curso técnico profissionalizante, como afirma a autora Cristina Vergutz.

\footnotetext{
Dessa forma a organização curricular [...] se coaduna com o eixo da formação integral, pois integra os saberes do curso médio e do curso técnico profissionalizante convergindo para uma prática organizativa de articulação entre a educação profissional técnica de nível médio integrada. Neste sentido, a prática pedagógica [...] apresenta-se como um projeto pedagógico com um horário escolar integrativo de Ensino Médio e Ensino Técnico e a confecção de dois diplomas: um para o curso de Ensino Médio e outro para o Curso de Ensino Técnico em Agricultura. (VERGUTZ, 2013, p. 115).
}

Compreende-se que a metodologia da Pedagogia da Alternância promove a integração dos saberes das diferentes áreas dos conhecimentos, bem como, os conhecimentos e práticas das realidades cotidianas dos estudantes e seus meios sociofamiliares, como destaca Begmani (2011, p. 20) ao dissertar sobre os princípios do funcionamento da alternância que "pressupõe contextualizar e integrar os sabres da realidade cotidiana com os saberes da formação geral e profissional. Ou seja, propõe-se 
integrar também os saberes das áreas.”. Assim, enxergamos que para além dos conhecimentos curriculares do ensino médio e do técnico profissionalizando, os saberes dos estudantes, família e meio social são considerados e desenvolvidos em igual importância aos demais.

Durante o estudo encontramos nos documentos oficiais das escolas do campo estudadas, as disciplinas que compõem a área do conhecimento das Ciências da Natureza (Biologia, Química e Física) incorporadas nos componentes curriculares do técnico profissionalizante. Tais como, a disciplina de Biologia é desenvolvida no componente curricular da Produção Vegetal, onde são estudadas as características das plantas a partir das cultivares que os estudantes produzem na propriedade familiar. Também são estudadas nesse componente, as técnicas de manejo mais adequadas a conservação ambiental e o aumento da produtividade do cultivo, bem como os nutrientes necessários as plantas que podem ser produzidos e incorporados a partir de matérias primas oriundas da propriedade familiar. Caracterizando assim, a concepção e a prática da Agroecologia expressa em outros componentes curriculares.

As disciplinas de Física e Química estão incorporadas no componente curricular intitulado Engenharias, onde são desenvolvidas temáticas referentes as construções e instalações rurais, desenho técnico e métodos e técnicas de pesquisas. Também no componente curricular, Solos e Adubação, são encontradas as disciplinas das Ciências da Natureza, tais como a Física e Química. Essas dão subsídio as discussões referentes a caracterização dos diferentes tipos de solo, sua origem, sua formação e composição, bem como, a delimitação e diferenciação dos diferentes perfis dos solos e caracterização do perfil cultural e suas propriedades, ainda, a correta coleta de amostras de solo bem como interpretar os resultados laboratoriais. Orientando as escolhas dos estudantes para cultivos mais adequados à determinados solos, respeitando assim a natureza e sua conservação, sem abdicar da produção de alimentos.

A partir dos Instrumentos Pedagógicos da Pedagogia da Alternância, entre eles, o Plano de Estudo, são desenvolvidas as temáticas emergentes dos estudantes a partir dos conhecimentos prévios destes. Partindo da pesquisa participativa por meio do diálogo com o espaço sociofamiliar o estudante apresenta suas compreensões e demandas, junto as problemáticas e hipóteses que serão destrinchadas em conjunto as áreas dos 
conhecimentos, proporcionando assim uma construção em sintonia e arrelias de conhecimentos ressignificados e robustos.

\section{CONSIDERAÇÕES FINAIS}

Muitas são as aprendizagens destes últimos anos, a partir de cenários conflituosos, devastados e polarizados. São regredidos em curto espaço de tempo, os tímidos avanços sociais que levaram anos a serem conquistados. As lutas, outrora, por direitos e conquistas são hoje lutas de resistências e sobrevivência. A Pandemia mundial trouxe luz as consequências dos descasos e retrocessos em que estamos vivendo e mesmo neste cenário caótico, ainda são promovidas violências sob a população brasileira, como o negacionismo científico e a morosidade dos investimentos em saúde e educação.

O projeto Cirandar: Rodas de investigação desde a escola da FURG compõe junto as demais ações de extensão das Universidades públicas um espaço de reflexão, discussão e proposição por um novo, emergente e necessário mundo. Projetos de extensão que fomentam a reflexão a partir da prática docente na educação básica, tão esquecida e desassistida e valorizam o potencial dos conhecimentos e saberes desses professores, de uma forma acalentadora e harmoniosa. E mesmo em tempos de Pandemia, o projeto Cirandar adaptou-se e promoveu potentes discussões de forma remota, demonstrando assim o poder de resiliência dos professores da educação pública.

Entre essas discussões, a pesquisa aqui apresentada possuiu o intuito de refletir sobre os currículos das escolas do campo, no que tange a Pedagogia da Alternância como proposta organizacional teórico metodológico sob o ensino de Agroecologia, na Educação do Campo. Assim foram apresentadas e descritas a partir dos documentos estudados as concepções e conceitos que embasam o trabalho dessas escolas do campo, bem como as características e interconexões que compõe o currículo escolar, na integração do currículo do ensino médio com o currículo do técnico profissionalizante. Demonstrando assim as potencialidades que as ciências da natureza junto as ciências agrárias possuem ao subsidiar o ensino da Agroecologia nessas escolas do campo, considerando a realidade e demandas dos estudantes por meio dos Instrumentos Pedagógicos. 


\section{AGRADECIMENTOS}

O presente trabalho foi realizado com apoio da Coordenação de Aperfeiçoamento de Pessoal de Nível Superior - Brasil (CAPES) - Código de Financiamento 001.

\section{REFERÊNCIAS}

BEGMANI, João Batista. Os CEFFAs e a Educação Média e Profissional Integrada. Texto elaborado para a Equipe Pedagógica Nacional dos CEFFAs do Brasil. Brasília: Rede dos CEFFAs/UNEFAB/ARCAFAR SUL/ARCAFAR NE/NO, setembro de 2011.

CALDART, Roseli Salete. Por uma Educação do Campo: traços de uma identidade em construção. In: KOLLING Edgar Jorge, CERIOLI Paulo Ricardo e CALDART, Roseli Salete, (Orgs.). Educação do Campo: identidade e políticas públicas. Brasília: Articulação nacional por uma educação do campo, 2002. (Coleção Por Uma Educação do Campo, n. ${ }^{\circ}$ ).

CALDART, Roseli Salete. Por uma educação do campo: traços de uma identidade em construção. In: ARROYO, Miguel, CALDART, Roseli Salete, MOLINA, Mônica Castagna. (Orgs.). Por uma educação do campo. Petrópolis: Vozes, 2009.

CAPORAL, Francisco Roberto. Agroecologia: uma nova ciência para apoiar a transição à agriculturas mais sustentáveis. In: CAPORAL, Francisco Roberto. COSTABEBER, José Antônio. PAULUS, Gervásio. (org.). Agroecologia: uma ciência do campo da complexidade. Brasília: DF. 2009.

COSTA, João Paulo Reis. Escola Família Agrícola de Santa Cruz do Sul EFASC: uma contribuição ao desenvolvimento da região do Vale do Rio Pardo a partir da Pedagogia da Alternância. Dissertação Mestrado em Desenvolvimento Regional, Universidade de Santa Cruz do Sul - UNISC, 2012.

EFASC. Plano de Curso do Ensino Médio e Técnico Profissionalizante. Santa Cruz do Sul, 2009.

EFASerra Gaúcha. Plano de Curso do Ensino Médio e Técnico Profissionalizante. Caxias do Sul, 2012. 
GIL, A. C. Métodos e técnicas de pesquisa social. São Paulo: Atlas, 2009.

MARTINS, Heloisa Helena T. Souza. Metodologia qualitativa de pesquisa. In: Educação e Pesquisa, São Paulo, v.30, n.2, maio/ago. 2004, p. 289-300.

VERGUTZ, Cristina Luisa Bencke. Aprendizagens na Pedagogia da Alternância da Escola Família Agrícola de Santa Cruz do Sul. 2013. 172f. Dissertação (Mestrado em Educação) - Programa de Pós-Graduação em Educação, Universidade de Santa Cruz do Sul (UNISC), Santa Cruz do Sul, 2013.

Recebido em: 18 de maio de 2021.

Aceito em: 08 de junho de 2021. 